\title{
CLINICOPATHOLOGICAL CHARACTERISTICS OF ACUTE INCLUSION BODY HEPATITIS OUTBREAK IN BROILER CHICKENS IN IRAN
}

\author{
A. KHODAKARAM-TAFTI ${ }^{1}, \mathrm{~K} . \mathrm{ASASI}^{2} \&$ F. NAMAZI ${ }^{1}$ \\ ${ }^{1}$ Department of Pathobiology, ${ }^{2}$ Department of Clinical Studies; School of \\ Veterinary Medicine, Shiraz University, Shiraz, Iran
}

\section{Summary}

Khodakaram-Tafti, A., K. Asasi \& F. Namazi, 2016. Clinicopathological characteristics of acute inclusion body hepatitis outbreak in broiler chickens in Iran. Bulg. J. Vet. Med., 19, No 2, 163-168.

\begin{abstract}
An outbreak of inclusion body hepatitis was noticed in $20 \%$ of the population of a flock of 20000 broiler chickens. The affected 14-day-old birds experienced $10 \%$ mortality during a period of one week. On 39 and 44 days of age, clinical infectious bursal disease and Newcastle disease with $5 \%$ and $15 \%$ mortalities occurred in the flock, respectively. Clinical signs of affected birds included depression, leg weakness and mild watery droppings. Grossly, only the affected liver was a friable and enlarged organ associated with petechial haemorrhages and multifocal gray-white to yellowish necrotic areas. Histopathologically, multifocal to coalescing necrosis of hepatocytes, remarkable large basophilic intranuclear inclusion bodies were diagnosed. In the present study, it seemed that the causative agent had produced acute disease without predisposing factors and it could be suggested that resulting immunosuppression was the trigger mechanism for subsequent infectious bursal disease (IBD) and Newcastle disease (ND) outbreaks.
\end{abstract}

Key words: broiler chicken, clinical sign, inclusion body hepatitis, outbreak, pathological lesions

Inclusion body hepatitis (IBH) was first described in the domestic chicken in 1963 then rapidly spread over the world (Helmboldt \& Frazier, 1963). It is an acute disease due to an infection by fowl adenovirus (Dar et al., 2012). Inclusion body hepatitis has economic importance because of the high mortality rate, contagiousness, immunosupression, the absence of an ef- fective treatment, lack of vaccination, resistance to common disinfectants and the widespread adenovirus nature.

The disease occurs mainly in chickens 3 to 7 weeks of age, but it has been reported in chickens less than 1 week old (Pilkington et al., 1997). As a consequence of failure to receive passive immunity, the disease can occur in very 
young birds. In these situations, a virulent adenovirus is transmitted vertically from an immunologically naïve hen infected during the laying period (Hoerr, 1996).

It is characterised by acute hepatic necrosis with the presence of intranuclear basophilic inclusion bodies in the hepatocytes. The sudden death in this syndrome may reach $10 \%$ in 3-4 days and usually returns to normal 5 days after the onset of clinical signs. All ages of chickens were found to be susceptible (Hess et al., 2000).

By electron microscopic studies, the presence of adenovirus-like particles in cases of hepatitis with necrosis and intranuclear inclusion bodies has been proven in various avian species, including the kestrel (Sileo et al., 1983), pigeon (Coussement et al., 1984), goose (Goryo et al., 1988), tawny frogmouth (Reece et al., 1985), merlin (Schelling et al., 1989), cockatiel (Scott et al., 1986) and in a peach-faced love-bird (Pass, 1987).

Some predisposing factors enhance the pathogenic potential of fowl adenovirus infection such as a poor environmental condition and management, bacterial infections, infectious bursal disease virus, chicken anemia virus and Marek's disease virus (McFerran et al., 1976; Toro et al., 2000; Ojkić et al., 2008), so it seems that the adenovirus can play a role as a secondary pathogen. Therefore, in usual outbreaks, immunosuppression induced by predisposing factors at an early age cause the disease in broiler chickens. This study describes clinical and pathological characteristics of outbreak of acute inclusion body hepatitis in broiler chickens in Iran.

An outbreak of a disease was noticed in $20 \%$ of the population of a flock of 20,000 Ross 308 broiler chickens. The affected farm was located in Kherameh city of Fars province, Iran. This flock was housed at a high density with a low level of biosafety management. For providing optimum environmental conditions, the house was equipped with central heaters, pad cooling systems and 6 fans. Wood shavings were used as litter. The broiler chickens were fed a commercial cornsoybean pelleted meal starter diet. The lighting programme was $23 \mathrm{~h}$ light and $1 \mathrm{~h}$ darkness at the onset of the outbreak. The flock was vaccinated against infectious bronchitis with a live vaccine, H120 strain via drinking water on 3 days of age then scheduled for vaccination against IBD and Newcastle disease (ND) based on related maternal immunity. The first vaccination against ND was on day 9 of age with a live B1 by eye drop route and an inactivated oil adjuvant vaccine simultaneously. The period of disease was about one week. Based on clinical signs, post mortem findings and certain paraclinical tests no concurrent infection or immune compromised status were observed in the flock during the clinical disease time frame.

The affected 14-day-old birds experienced $10 \%$ mortality during the period of disease. A number of dead birds were necropsied. At necropsy, gross changes were noticed only in the liver. Tissue samples from liver were collected in $10 \%$ neutral buffered formalin and embedded in paraffin. Sections were made at $5 \mu \mathrm{m}$ thickness and stained by haematoxylin and eosin and studied under light microscope. The flock was followed up until slaughtering. On 39 days of age, clinical IBD occurred in the flock and resulted in 5\% mortality. Subsequently ND has occurred on 44 days of age with $15 \%$ mortality despite routine vaccination against these two diseases.

The clinical signs of affected birds included depression, leg weakness and mild 
watery droppings. The livers of affected chickens were friable, swollen and enlarged associated with scattered petechial haemorrhages and multifocal to widespread discoloration of gray-white to yellowish necrotic areas (Fig. 1).

Histopathologically, subcapsular haemorrhages and widespread disruption of hepatic architecture as multifocal to coalescing necrosis of hepatocytes with variable degrees of pyknosis and karyorrhexis were seen. Cell swelling and mild to moderate fatty changes were observed in the hepatocytes adjacent to necrotic foci. Also, large basophilic intranuclear inclusion bodies completely filling enlarged nuclei were diagnosed in some of the hepatocytes (Fig. 2). With lesser occurrence, basophilic intranuclear inclusion bodies with clear halos were found in the hepatocytes. On the basis of histopathological characteristics, inclusion body hepatitis was diagnosed.

The liver is the primary organ affected and the histopathological technique easily confirms the disease by the presence of intranuclear inclusion bodies in hepatocytes. The main pathological findings of the present study are coincident with those previously described (Sandhu et al., 1994; Pilkington et al., 1997; Gaba et al., 2010; Hosseini \& Morshed, 2012; Rahimi \& Siavosh Haghighi, 2015). In this study, histopathological lesions of the liver did not reveal eosinophilic intranuclear inclusion bodies described by some authors (Sileo et al., 1983; Coussement et al., 1984; Riddell, 1984; Pass, 1987; Goryo et al., 1988; Schelling et al., 1989; Rahimi \& Siavosh Haghighi, 2015) in cases of adenovirus IBH. Ramis et al. (1992) have reported an epizootic outbreak of inclusion body hepatitis in eclectus parrots (Eclectus roratus) in Spain.

An immunocompromised state could be induced by certain viral diseases, stress and poor environmental conditions, which can lead to an increase of the pathogenicity of adenoviral infection. In usual outbreaks, the common causes of immunosuppression in broiler chickens are subclinical infectious bursal disease and

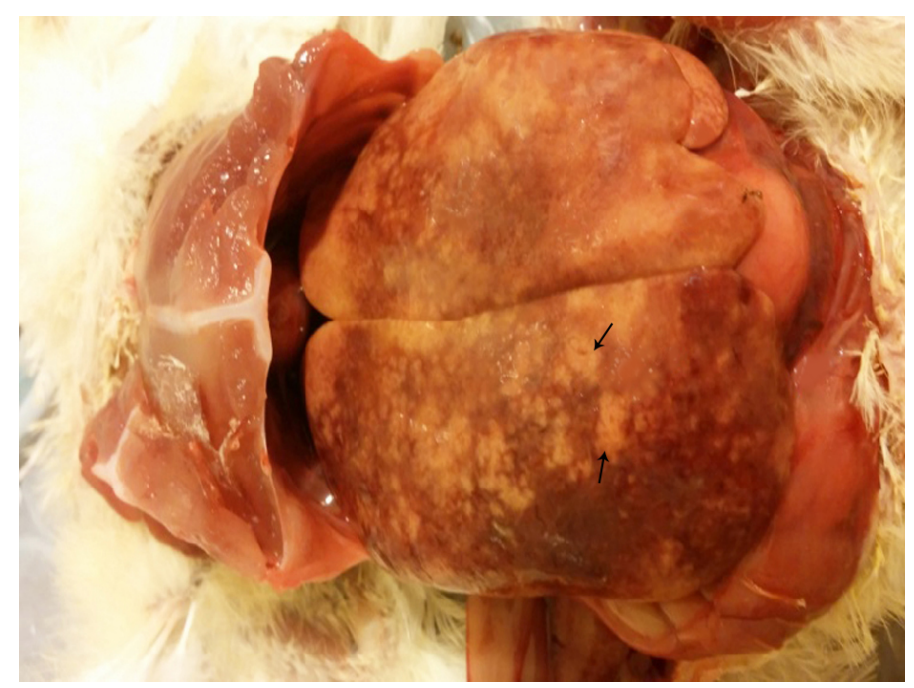

Fig. 1. Enlarged liver with multifocal discoloration of gray-white to yellowish necrotic foci (arrows). 


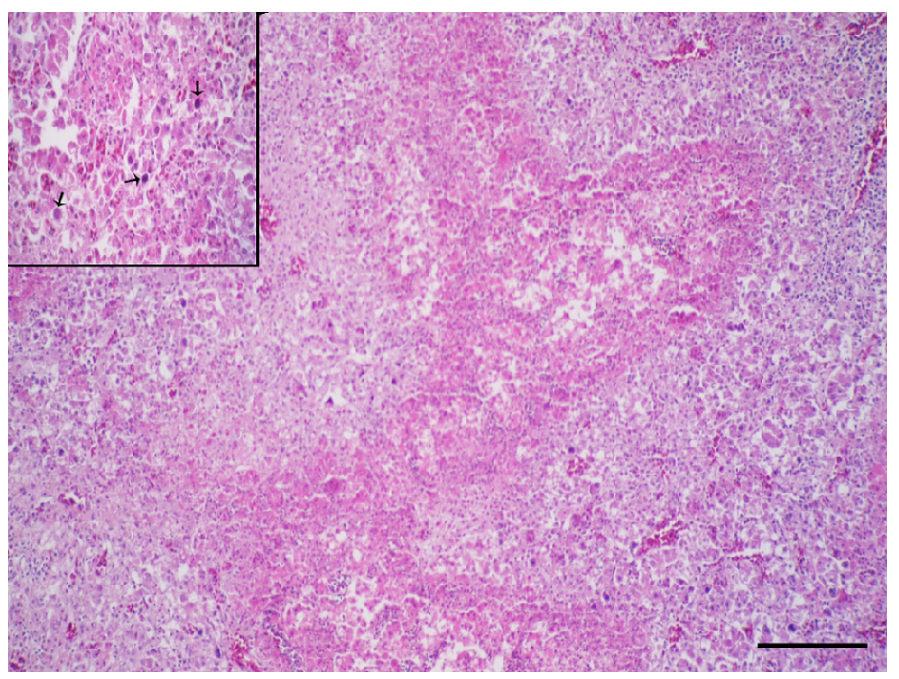

Fig. 2. Multifocal to coalescing necrosis of hepatocytes is seen. $H \& E$, bar $=55 \mu \mathrm{m}$. Inset shows large basophilic intranuclear inclusion bodies completely filling enlarged nuclei (arrows).

Marek disease at an early age (Hoerr, 1996). Zadravek et al. (2011) have reported an outbreak of inclusion body hepatitis with $2.2 \%$ mortality rates in a broiler flock of 12,000 birds in Slovenia. The causative agent was identified as fowl adenovirus type $8 \mathrm{~b}$ and infectious bursal disease virus and infectious bronchitis virus were identified in the flock as well. Mettingfo et al. (2014) have reported inclusion body hepatitis/hydropericardium syndrome (IBH/HPS) outbreak due to fowl adenovirus group 1 in Brazilian broiler flocks.

Some fowl adenoviruses have been described as inducing immunosuppression in chickens without any other predisposing factors. For instance, Schonewille et al. (2008) demonstrated by experimental infection that fowl adenovirus-4 caused a depletion of B and T lymphocytes in lymphoid organs in SPF chickens. Some studies in Canada supported the hypothesis that IBH in broilers is a primary disease without known immunosuppressive agents (Gomis et al., 2006). Also, previous stu- dies in Iran did not mention any cooccurring disease or other predisposing factor in studied flocks (Hosseini \& Morshed, 2012; Rahimi \& Siavosh Haghighi, 2015). Hosseini \& Morshed (2012) identified serotype 11 fowl adenovirus as the causative agent of IBH. In the present study, it seems that the virus as a primary pathogen induced immunosuppression without any other predisposing factors. The vaccination of the flock against ND was very strict with several live vaccines and a killed one because very virulent ND was prevalent in the area, however the flock experienced very virulent ND with about $15 \%$ mortality probably due to immunosuppression induced first by IBH and subsequently, by IBD.

The only way to control of this disease seems to be the prophylactic vaccination of broiler-breeder flocks and implementation of a strong biosecurity programme to prevent contamination of the environment and birds on broiler farms.

In conclusion, this study describes an outbreak of acute inclusion body hepatitis 
without predisposing factors in a flock of broiler chickens. It could be supposed that immunosuppression due to causative agent was the trigger mechanism for subsequent infectious bursal disease and Newcastle disease outbreaks in the same flock.

\section{REFERENCES}

Coussement, W., R. Ducatelle, P. Lemahieu, R. Froyman, L. Devwese \& J. Hoorens, 1984. Pathologie van adenovirus-infekties bij duiven. Vlaams Diergeneeskundig Tijdschrift, 53, 277-283.

Dar, A., S. Gomis, I. Shirley, G. Mutwiri, R. Brownlie, A. Poter, V. Gerdts \& S. K. Tikoo, 2012. Pathotypic and molecular characterization of a fowl adenovirus associated with inclusion body hepatitis in Saskatchewan chickens. Avian Diseases, 56, 73-81.

Gaba, A., H. Parmar, J. K. Pal \& K. S. Prajapati, 2010. Isolation, identification and molecular characterization of inclusion body hepatitis virus. Veterinary World, 3, 415-417.

Gomis, S., R. Goodhope, D. Ojkić \& P. Willson, 2006. Inclusion body hepatitis as a primary disease in broilers in Saskatchewan, Canada. Avian Diseases, 50, 550555.

Goryo, M., Y. Ueda, T. Umemura, A. Haruna \& C. Itakura, 1988. Inclusion body hepatitis due to Adenovirus in pigeons. Avian Pathology, 17, 391-401.

Helmboldt, C. F. \& M. N. Frazier, 1963. Avian hepatic inclusion bodies of unknown significance. Avian Diseases, 7, 446-450.

Hess, M., 2000. Detection and differentiation of avian adenoviruses: A review. Avian Pathology, 29, 195-206.

Hoerr, F. J., 1996. Liver. In: Avian Histopathology, ed C. Riddell, $2^{\text {nd }}$ edn, Tallahassee: Rose Printing, pp. 144-166.

Hosseini, H. \& R. Morshed, 2012. Molecular identification of fowl adenovirus associ- ated with inclusion body hepatitis in Iran. Iranian Journal of Virology, 6, 7-12.

Mettifogo, E., L. F. N. Nuñez, S. H. Santander Parra, G. S. Astolfi-Ferreira \& A. J. Piantino Ferreira, 2014. Fowl adenovirus Group I as a causal agent of inclusion body hepatitis/hydropericardium syndrome (IBH/HPS) outbreak in Brazilian broiler flocks. Pesquisa Veterinária Brasileira, 34, 733-737.

McFerran, J. B., R. M. McCracken, T. J. Connor \& R. T. Evans, 1976. Isolation of viruses from clinical outbreaks of inclusion body hepatitis. Avian Pathology, 5, 315-324.

Ojkić, D., E. Martin, J. Swinton, J. P. Vaillancourt, M. Boulianne \& S. Gomis, 2008. Genotyping of Canadian isolates of fowl adenoviruses. Avian Pathology, 37, 95100.

Pass, D. A., 1987. Inclusion bodies and hepatopathies in psittacines. Avian Pathology, 16, 581-597.

Pilkington, P., T. Brown, P. Villegas, B. McMurray, R. K. Page, G. N. Rowland \& S. G. Thayer, 1997. Adenovirus-induced inclusion body hepatitis in four-day-old broiler breeders. Avian Diseases, 41, 472474.

Rahimi, M. \& Z. M. Siavosh Haghighi, 2015. Adenovirus-like inclusion body hepatitis in a flock of broiler chickens in Kermanshah province, Iran. Veterinary Research Forum, 6, 95-98.

Ramis, A., M. J. Marlasca, N. Majo \& L. Ferrer, 1992. Inclusion body hepatitis (IBH) in a group of eclectus parrots (Eclectus roratus). Avian Pathology, 21, 165-169.

Reece, R. L., D. A. Pass \& R. Butler, 1985. Inclusion body hepatitis in a tawny frogmouth (Podargus strigoides: Caprimulgiformes). Australian Veterinary Journal, 62, 426.

Riddell, C., 1984. Viral hepatitis in domestic geese in Saskatchewan. Avian Diseases, 28, 774-782. 
Clinicopathological characteristics of acute inclusion body hepatitis outbreak in broiler chickens ...

Sandhu, B. S., H. Singh \& B. Singh, 1994. Prevalence and pathology of inclusion body hepatitis in chicken in Punjab. Indian Veterinary Journal, 71, 438-442.

Schelling, S. H., D. S. Garuck \& J. Alroy, 1989. Adenoviral hepatitis in a merlin (Falco columbarius). Veterinary Pathology, 26, 529-530.

Schonewille, E., A. Singh, T. W. Göbel, W. Gerner, A. Saalmüller \& M. Hess, 2008. Fowl adenovirus (FAdV) serotype 4 causes depletion of $B$ and $T$ cells in lymphoid organs in specific pathogen-free chickens following experimental infection. Veterinary Immunology and Immunopathology, 121, 130-139.

Scott, P. C., R. J. Condron \& R. L. Reece, 1986. Inclusion body hepatitis associated with adenovirus-like particles in a cockatiel (Psittaciformes; Nymphicus hollandicus). Australian Veterinary Journal, 63, 337-338.

Sileo, L., J. C. Franson, D. L. Graham, C. H. Domermuth, B. A. Rattner \& O. H. Pattee, 1983. Hemorrhagic enteritis in captive American kestrels (Falco sparverius). Journal of Wildlife Diseases, 19, 224-247.

Toro, H., C. Gonzales, L. Cerda, M. Hess, E. Reyes \& C. Geissea, 2000. Chicken anemia virus and fowl adenoviruses: Association to induce the inclusion body hepati- tis/hydropericardium syndrome. Avian Diseases, 44, 51-58.

Zadravec, M., B. Slavec, U. Krapež, G. L. Kaján, J. Račnik, P. Juntes, R. Juršič Cizerl, M. Benkő \& O. Z. Rojs, 2011. Inclusion body hepatitis associated with fowl adenovirus type $8 \mathrm{~b}$ in broiler flock in Slovenia - A case report. Slovenian Veterinary Research, 48, 107-113.

Paper received 10.05.2015; accepted for publication 15.06.2015

\section{Correspondence:}

F. Namazi

Department of Pathobiology,

School of Veterinary Medicine,

Shiraz University, Shiraz, Iran

tel: +987132286950

fax: +987132286940

e-mail: fnamazi@shirazu.ac.ir 